\title{
Setting the research agenda for abortion in Africa and Asia
}

\section{Clinical article}

Scott, R.H., Filippi, V., Moore, A.M., Acharya, R., Bankole, A., Calvert, C., Church, K., Cresswell, J.A., Footman, K., Gleason, J., Machiyama, K., Marston, C., Mbizvo, M., Musheke, M., Owolabi, O., Palmer, J., Smith, C., Storeng, K., and Yeung, F.

\section{Author information}

Rachel H Scott*

Research Fellow

London School of Hygiene \& Tropical Medicine

London

United Kingdom

Veronique Filippi

Professor in Maternal Health and Epidemiology

London School of Hygiene \& Tropical Medicine

London

United Kingdom

Ann M Moore

Principal Research Scientist

Guttmacher Institute

New York

United States

Rajib Acharya

Associate

Population Council

New York

United States

Akinrinola Bankole

Director of International Research

Guttmacher Institute

New York

United States

Clara Calvert

Assistant Professor

London School of Hygiene \& Tropical Medicine

London

United Kingdom

Kathryn Church

Senior Scientific Manager

Marie Stopes International 
London

United Kingdom

Jenny A Cresswell

Assistant Professor

London School of Hygiene \& Tropical Medicine

London

United Kingdom

Katharine Footman

Research Portfolio Manager

Marie Stopes International

London

United Kingdom

Joanne Gleason

Associate Director, Reproductive Health Program

Population Council

New York

United States

Kazuyo Machiyama

Assistant Professor

London School of Hygiene \& Tropical Medicine

London

United Kingdom

Cicely Marston

Associate Professor

London School of Hygiene \& Tropical Medicine

London

United Kingdom

Mike Mbizvo

Director, Population Council Zambia; Senior Associate, Reproductive Health program

Population Council

Lusaka

Zambia

Maurice Musheke

Research Manager

Population Council

Lusaka

Zambia

Onikepe Owolabi

Senior Research Scientist

Guttmacher Institute

New York 
United States

Jennifer Palmer

Assistant Professor

London School of Hygiene \& Tropical Medicine

London

United Kingdom

Christopher Smith

Assistant Professor

London School of Hygiene \& Tropical Medicine

London

United Kingdom

Katerini Storeng

Associate Professor

University of Oslo

Oslo

Norway; and

Honorary Lecturer

London School of Hygiene \& Tropical Medicine

London

United Kingdom

Felicia Yeung

Independent

London

United Kingdom

${ }^{*}$ Corresponding author:

Rachel H Scott

London School of Hygiene \& Tropical Medicine

Keppel Street

London WC1E 7HT

Telephone/fax: 02076127912

E-mail: rachel.scott@lshtm.ac.uk

Word count: 3,795 words

Keywords: Abortion; Medical Abortion; Africa; Asia; Quality of Care; Policy; Measurement 
Synopsis: This commentary proposes advances in research on abortion necessary for addressing the health and wellbeing of populations and meeting the UN Sustainable Development Goals. 


\section{Abstract}

Provision of safe abortion is widely recognized as vital to addressing the health and wellbeing of populations. Research on abortion is essential to meet the UN Sustainable Development Goals. We brought together researchers in population health from university, policy and practitioner contexts working on two multidisciplinary projects on family planning and safe abortion in Africa and Asia for a workshop to discuss the future research agenda on abortion. Research on care seeking behavior, supply of abortion care services, and the global and national policy context will help improve access to and experience of safe abortion services. A number of areas have potential in designing intervention strategies, including clinical innovations, quality improvement mechanisms, community involvement, and task sharing. Research on specific groups, including adolescents and young people, men, populations affected by conflict, marginalized groups, and providers, may increase our understanding of provision, access to and experiences of abortion. Methodological and conceptual advances, for example in measurement of abortion incidence and complications and client satisfaction, conceptualizations of abortion access and care, and methodologies to follow women who have abortions, will improve the accuracy of our measurements of abortion, and add to our understanding of women's experiences of abortion and abortion care. 
Synopsis: This commentary proposes advances in research on abortion necessary for addressing the health and wellbeing of populations and meeting the UN Sustainable Development Goals. 


\section{Setting the research agenda for abortion in Africa and Asia}

Research on abortion is essential if we are to meet the UN Sustainable Development Goals (SDGs) [1]. Abortion is an important cause of maternal mortality: not only does unsafe abortion account for nearly one-fifth of all maternal deaths worldwide but complications of abortion increased as a proportion of causes of maternal deaths between 1990 and 2015 [2].Unsafe abortion has economic costs for health systems, women and their families $[3,4]$, as well as social costs, for example through stigma experienced by women and their families, or the impact on family members of death or severe morbidity from abortion [4]. Provision of safe abortion is widely recognized as vital to addressing the health and wellbeing of populations [4]. Research on abortion can contribute to multiple SDGs including those relating to health and wellbeing, gender equality and poverty reduction.

Research on abortion is particularly crucial in the context of the hostile policy environment created by the reinstatement of the US government's Mexico City Policy which forbids foreign non-governmental organizations receiving US government money from providing or providing information about safe abortion services [5]. This has implications for provision and research on family planning in general and abortion in particular. An analysis of Demographic and Health Survey data showed that the reinstatement of the Mexico City Policy by the George W Bush administration in 2004 led to an increase in abortion rates in sub-Saharan Africa [6]. The policy's reinstatement and even stricter interpretation by the Trump administration in 2017 has already had marked effects on the willingness of policymakers and stakeholders to enact globally agreed reproductive health strategies in some African settings [7]. Its further effects on abortion and family planning access remain to be studied. 
Although use of modern methods of family planning has increased substantially in many low- and middle-income countries over the last decade, unmet need remains high and the number of women wanting to regulate their fertility is increasing [8] There has been a decline in estimated abortion rates in high-income countries, yet estimated rates are stable or even increasing in Africa and Asia [9]

The availability of medical abortion (MA) has revolutionized the way abortion services are provided, and has improved access to abortion. In low-resource settings with few trained surgical providers, MA provides a safe and effective non-surgical option [10]. MA drugs are widely available from pharmacies and drug sellers; even in restrictive settings, medication such as misoprostol can be purchased over the counter for other indications and used to induce an abortion [11]. This change in the way abortions are taking place also brings about many new research questions as well as a need for new methodological approaches.

We brought together population health researchers from university, policy and practitioner contexts working on two multidisciplinary DFID-funded projects on family planning and safe abortion in Africa and Asia for a workshop to discuss the future research agenda on abortion in these geographic areas. Workshop attendees included academics researching - broadly - access to abortion services, quality of abortion care and measurement of abortion; researchers from organizations providing reproductive health services, with expertise in implementing and evaluating interventions; and individuals with expertise in reproductive health policy and programming. The Strengthening Evidence for Programming on Unintended Pregnancy (STEP-UP) project is a six year research consortium aiming to generate policy-relevant research for improving access to family planning and safe abortion services to reduce unintended pregnancy in five countries in Africa and South Asia 
(http://stepup.popcouncil.org). Eva-PMDUP was an evaluation of the Prevention of Maternal Deaths and Unwanted Pregnancies (PMDUP) program implemented in fourteen countries in Africa and Asia between 2011 and 2016

(http://mnhgroup.Ishtm.ac.uk/eva-pmdup). These two projects cumulatively gathered a wealth of information about family planning and abortion. As the projects came to a close, the research teams took the opportunity to share lessons learned and insights about where the research agenda should go from here. The meeting focused on abortion: while contraception helps avoid unintended pregnancies, the emphasis of the workshop was on the women who have unintended pregnancies and their care pathways.

The meeting covered three broad, but complementary, strands: Access, Quality and Policy. Participants presented research questions arising from the two projects. Research questions were drawn not solely from the findings of projects, but also from participants' reflections on their research experiences during the projects, and supported by their reading of the current research literature. Subsequently, in small groups, participants discussed the research questions presented, and reflected on the novelty, feasibility and public health impact of each of the specific research questions raised, as well as their relevance to the SDGs, key audiences and policy and programmatic implications. Each small group fed back the key points of their discussion to the whole group. The group assembled considered each research question against the criteria above, in an effort to reach a group consensus on key themes within the research questions identified. To qualify for inclusion, it was not necessary that each research question fulfil all these criteria, but rather the criteria were cumulatively weighted against each other. For example, some of the questions included may present substantial methodological challenges, but were considered to 
have significant public health implications if they could be addressed, whilst others may have less public health impact but would be straightforward and time-efficient to address. References included below rely heavily on the publications which came out of both the STEP-UP and Eva-PMDUP projects.

We discuss the key research questions identified during the workshop below.

\section{What do we need to know to improve access to and the quality of comprehensive abortion services?}

In order to develop programs to reduce recourse to unsafe abortion and its consequences, it is necessary to understand barriers and facilitators to the use of safe abortion services. Abortion services comprise both safe abortion care (SAC) and post-abortion care (PAC). Together, these packages of services are called comprehensive abortion care (CAC). In restrictive settings, services mostly comprise PAC [12].

\subsection{Factors shaping care-seeking behavior}

We identified many research gaps in factors that affect women's abortion careseeking behaviors. For example, even in less-restrictive contexts, knowledge of the legal grounds under which an abortion may be obtained and where abortion services (including medical abortion) can be safely obtained can be very incomplete [13,14]. Family members' lack of support can limit women's choices [15], and gender inequality in addition to cultural stigma may restrict access to available abortion services [16]. Delays in identifying and confirming a pregnancy may prevent women's timely access to abortion services [17]. Women may experience abortion symptoms differently, particularly after medical abortion, and may understand sideeffects differently as well as define morbidity differently, leading to differences in 
post-abortion care-seeking behaviors. Further research into determinants of careseeking behavior will help inform interventions to improve access to services for those that need abortion care.

\subsection{Supply of abortion care services}

More research is needed on the availability, quality and outcomes of services and how these might be improved. Little is known about who is providing abortion services and how they are providing those services outside formal health services, or the safety of the services being provided within facilities in contexts with fragile healthcare systems, provider shortages and inadequate supply chains. Evidence suggests that there is increasing use of MA drugs purchased in the informal sector and in some middle-income countries, the internet, but there are limited data on this [18-20]. In addition, little is known about outcomes for individuals who self-manage medical abortion [21]. Our work suggests that information provided by pharmacies and drug sellers might be insufficient with regard to the correct regimen and the warning signs that should prompt medical treatment $[22,23]$ (Box 1). Hostility on the part of pharmacy workers [19] and demands for excessively high medical provider fees [24] have also been documented, including fees for services that should be free of charge [25]. This has also been documented in public and teaching as well as private hospitals [24]. It is likely that providers do this when they perceive the woman to be willing to pay because the provider perceives her as someone vulnerable to exploitation, either because she does not know that the services should be free or because she is attempting to circumvent the law to protect her secrecy and potentially avoid social stigma for having an abortion. Unregulated clinics and alternative medical practitioners are popular among many women in some countries [26], and more research is needed to understand why women choose these 
providers in settings where safe services are provided, and the quality of care they receive. Post-abortion contraceptive use is low, whether the client obtained a surgical abortion in a health facility or a medical abortion in the community [27]. Qualitative research is needed to explore women's experiences of and satisfaction with post-abortion contraceptive services, including the quality of counselling, to identify what might be most effective in delivering both post-abortion contraception and post-abortion contraceptive counselling in different settings (e.g. community, clinic, hospital).

\subsection{Interface between demand and supply}

Links between demand and supply of abortion care need to be investigated: how services fit into women's lives, and how perceptions of quality and risk determine use of abortion care services. Access to and use of abortion services and post-abortion care may be a function of quality of care (e.g. waiting times, provider attitudes, privacy). It may be possible to link a quality score of a facility to a score of geographical access to a facility, in order to identify barriers to service use that are related to quality. It is important to understand the economic cost of abortion for individuals and families, particularly how they gather the financial resources to pay for an abortion, how this affects their timely access to abortion care, and the longerterm implications for them of the financial outlay [28]. The relationship between expansion of medical abortion and availability should be examined.

\subsection{National and global policy context}

The Eva-PMDUP project conducted an in-depth policy analysis in multiple countries, three of which have been published so far $[7,29,30]$. There are a number of questions remaining about how national and global policy contexts determine 
availability, use and experiences of abortion services. How do anti-choice groups, which have recently consolidated transnational advocacy networks and political blocs in international spaces, influence policy debates and popular discourse in different settings and what strategies do they use [5]? How do the global and national policies related to public, private and NGO sectors' provision of abortion and the distribution of medical abortion drugs online and in informal markets affect women's access and experiences of an induced abortion? These questions are particularly pertinent now given President Trump's re-instatement of the Mexico City Policy.

\section{Which areas should be the focus of intervention?}

We identified a number of interventions that may help reduce recourse to unsafe abortion and improve quality of abortion care.

\subsection{Clinical innovations}

Evaluations of clinical innovations are needed to inform the evidence base on effective service delivery. These might include cervical priming, pain management in later trimester abortions, and self-administered DMPA (Sayana Press) learned at the time of abortion. Improving access to home pregnancy testing to enable women to confirm pregnancy at earlier gestations, which is associated with fewer complications $[17,31]$ could lead to a reduction in abortion morbidity and mortality.

\subsection{Quality improvement mechanisms}

Audits of deaths or near-miss mortality related to abortion may help elucidate where there are deficiencies in good quality abortion care and how these could be addressed (Box 2), possibly using a modified version of the three delays model [32] 
(see 4.2 below). Quality improvement interventions should also focus on respectful care (see 4.3 below), and may look to the field of maternity care for suggestions of how this could be achieved. A key area for quality improvement is in how best to deliver post-abortion contraceptive counselling. Our work has found that provision of information on post-abortion contraception by pharmacists and drug sellers is low [33], and little is known about how best to deliver post-abortion contraception among women who purchase medical abortion drugs from these sources. Another issue is how best to integrate services, for example care for victims of sexual and genderbased violence, with abortion care.

\subsection{Community involvement}

Research is needed to explore which elements of community involvement in planning, delivering and evaluating reproductive health services best improve access to and quality of abortion care. Examples of possible forms of community involvement include participatory learning and action techniques where communities and key stakeholders such as service providers work to identify and prioritize problems, develop and implement plans to address them, evaluate the result, and identify what course of action to take to continue to improve the situation [34]. Other options include inviting members of the community to participate in discussions about how to improve services. This is important to study carefully because of the sensitivities involved in this area.

\subsection{Task-sharing}

Even in countries where abortion is legal, provision is limited by a lack of trained providers. Task-sharing in abortion care including management of abortion and postabortion care, management of minor complications, and post-abortion contraceptive 
counselling and provision has the potential to improve both access to and acceptability of abortion services. Some task-sharing in abortion services is already recommended by the WHO [21], but more rigorous research is needed to assess the safety, feasibility and acceptability of task-sharing of first trimester abortion services to lay health workers, pharmacists, pharmacy workers, and women themselves.

\section{How can research on specific groups increase our understanding of abortion?}

Some specific groups are particularly important for research on abortion, either because they are marginalized with regard to access to care, or because they play a role in shaping access to and experiences of abortion.

\subsection{Adolescents and young people}

Our research has highlighted the need to improve adolescents' and young people's access to abortion care [35]. To do this, we need to better understand their pathways to access (or failure to access) services, and the potential impact of medical abortion to change adolescents' and young people's access to abortion in restrictive legal contexts [36].

\subsection{Men}

Many women experience relationship problems as a result of unintended pregnancy or abortion, often with the partner denying paternity or refusing involvement [15]. Future research could explore men's perceptions of responsibility for abortion, as well as understanding contexts where men are currently engaged and evaluating interventions that engage with men in the provision of abortion. 


\subsection{Populations affected by conflict}

The health of women fleeing war or natural disasters is particularly threatened by weak sexual and reproductive health services, as well as gender-based and sexual violence [37]. Service provision changes rapidly as regions move in and out of different phases of armed conflict, as may political discourses about gender, reproduction and the legitimacy of different categories of providers which affects supply [29]. More research is needed on both demand for and opportunities to provide quality abortion care in crisis situations, including how best to reach mobile populations.

\subsection{Marginalized groups}

Marginalized people are not necessarily those who live in poorer households, and those who do not access services are not necessarily those living in poorer areas of the country. Future research might explore abortion in the context of different conceptualizations of vulnerability and marginalization, for example marginalization in terms of ethnicity, legal status, geography, marital status, age or disability [38] to improve understanding of barriers to safe abortion care.

\subsection{Providers}

Health care providers have a crucial role to play in the availability and quality of abortion care. Limited research has examined the experiences of the individuals who provide abortion care, and the stigma and professional challenges they may experience. Studies suggest that providers often have reservations about providing abortion care [39], and mechanisms to help providers to cope with stigma and stress are urgently needed. Further research is needed to understand how best to do this, 
and to evaluate the impact on provider and client experiences, and quality of care, of interventions to support abortion providers.

\section{How might methodological or conceptual advances improve our understanding of safe provision of abortion and women's experiences of abortion?}

Abortion is a sensitive topic and both women and providers are often unwilling to participate in research. Innovations in the conceptualization and measurement of abortion are important in order to improve the accuracy of our measurements of abortion, and to add to our understanding of the quality of the abortion care that women receive.

\subsection{Measurement of abortion incidence and complications}

Without accurate measurement of the incidence of abortion and abortion complications, it is challenging to measure changes in abortion safety. In surveys, careful wording of questions and use of more private interview methods such as audio computer assisted self-interview (ACASI) might improve reporting by women who have had abortions [40]. Inclusion of abortion questions in innovative ways (such as asking about abortion along with a long list of other medical care) may also increase abortion reporting. Using near-miss cases (women who have had very severe complications from abortion, with a high risk of death) has been shown to be a promising indicator of unsafe abortion, and depending on the quality of the medical records, can be measured using medical records data [41]. There is likely to be a reduction in severe morbidity from abortion complications as medical abortion becomes more widespread. Other ways of measuring abortion incidence include the 
Confidants Method [42], which can reduce reporting bias as women speak about the abortion experience of friends or family members, rather than themselves.

Respondent driven methodologies, which combine snowball sampling with a mathematical model to account for the fact that the sample was collected in a nonrandom way [43], can also shed light on abortion incidence and care-seeking.

\subsection{Three delays model adaptation}

The three-delays model [32] identifies three main factors that prevent women from accessing care: delays in seeking care, delays in reaching care and delays in receiving adequate care. An adaptation of this to abortion care may be a useful overarching framework for understanding abortion care-seeking behavior and identifying areas for research and intervention.

\subsection{Respectful care model adaptation}

The model of respectful care, that is that maternal care should be humane and dignified, and be expanded beyond the prevention of morbidity or mortality to include respect for women's fundamental human rights, is becoming more recognized in maternal health [44]. Adaptation of this model for abortion research may be useful in identifying areas for improvement.

\subsection{Methodologies to follow women who use drug sellers}

Reporting the outcomes of women who use medical abortion purchased from pharmacies and drug sellers has presented significant measurement challenges as identifying, recruiting and following up these women is difficult [45]. This is evidenced in our research in Bangladesh, where we conducted a prospective cohort study of women using menstrual regulation medications purchased from pharmacies [22]. New methodologies need to be tested such as recruiting using research assistants 
based in pharmacies or offering financial incentives to providers to improve recruitment, or the use of mobile phone technologies to improve retention.

\subsection{Developing measures of client satisfaction}

Client satisfaction is a useful measure of service quality but is frequently measured using exit interviews, which are prone to courtesy bias [46]. New ways of measuring client satisfaction might provide a more accurate indicator of quality of care (Box 3 ).

\subsection{Mobile phone technologies}

Mobile phones may have the potential to improve both supply (for example, supporting pharmacists in their provision of medical abortion by giving them easy to access information or by allowing providers to request medical abortion or manual vacuum aspiration equipment via mobile applications) and demand-side factors (for example, by measuring client satisfaction by SMS or providing information on instructions for use of medical abortion, through providing information and reminders about follow-up care post-abortion or post-abortion contraception) of abortion care [47].

\section{Conclusion}

The research themes we identify cohere with the agenda put forward following the Africa Regional Conference on Abortion (November 29th - December $2^{\text {nd }} 2016$, Addis Ababa, Ethiopia)[48], which calls for an expansion of the evidence base to inform better policies and programs. This agenda highlights many similar research areas of importance, including: abortion stigma, the social and economic barriers individuals face in accessing safe abortion, the potential for task sharing, measuring quality of abortion services, and the needs of survivors of violence including those in humanitarian settings. 
The research questions we propose highlight the need to understand the determinants of demand for abortion care, how availability and quality might be improved, and the interface between demand and supply. Improving access to and quality of abortion care will reduce maternal mortality from complications of unsafe procedures. Developing new technologies may help empower women to selfmanage medical abortion. Finally, individuals must have full bodily autonomy to regulate their fertility, pursue opportunities for education and employment, and achieve overall health, wellbeing and productivity [49]. Research addressing these themes will be essential to meeting the SDGs. We issue a call to all researchers to participate in working to answer these pressing questions so that the next generation of women will not experience the same levels of morbidity and mortality from unsafe abortion as this generation. 
Box 1

Pharmacy provision of medical abortion is likely to continue to expand, and has the potential to reduce mortality and morbidity associated with unsafe abortion. However, studies suggest that in both Africa and Asia, ineffective medications are often sold, and information on the correct drug regimen and advice in the event of complications provided by drug sellers is often poor $[11,22,23,50,51]$. To further reduce harm from unsafe abortion, research is needed on both the outcomes of women who self-manage medical abortion and ways to improve women's experiences of self-management of medical abortion. These might include training for drug sellers, improvements to packaging of the drugs, and hotlines for information provision [50].

Box 2

Audits are frequently used in maternal health as a monitoring tool to identify areas of care that can be improved, develop recommendations and monitor improvements [52]. Audits have been successful in helping to reduce childbirth-related deaths in low-income countries [53]. In contexts where mortality from abortion is high, such as Zambia, audits of death or near-miss mortality from abortion, using hospital-based surveillance infrastructure, may help understand where there are deficiencies in good quality abortion care and how these could be addressed in order to reduce unsafe abortion. In contexts where abortion mortality is low, such as India, surveillance structures may be better placed in the community and the informal, private sector.

Box 3 
Novel ways of measuring client satisfaction as a measure of service quality might include formative research to identify constructs of dis/satisfaction in the context of abortion services; modelling the effects on non-response bias in follow-up services and developing techniques to reduce non-response and/or adjust for it; and exploring the potential for the use of ACASI surveys in centers to measure client satisfaction. 


\section{Acknowledgments}

This workshop was funded by the UK Department for International Development under Grant PO 5695.

\section{Conflict of interest}

The authors declare no conflict of interest.

\section{Author contributions}

RHS was lead author and drafted successive versions of the paper, with input from VF and AMM. All other authors participated in the meeting, commented on and edited drafts and approved the final version of the paper. 


\section{References}

[1] IPAS. Women's access to safe abortion in the 2030 Agenda for Sustainable Development: Advancing maternal health, gender equality, and reproductive rights. IPAS; 2015.

[2] Graham W, Woodd S, Byass P, Filippi V, Gon G, Virgo S, et al. Diversity and divergence: the dynamic burden of poor maternal health. Lancet 2016;388:2164-75. doi:10.1016/S0140-6736(16)31533-1.

[3] WHO. Safe abortion: Technical Policy and Guidance. Geneva: WHO; 2012.

[4] Singh S, García SG, Guillaume A, Okonofua F, Prata N. The health, social, and economic consequences of unsafe abortion: Papers presented at an IUSSP Seminar, Mexico, 2010. Int J Gynecol Obstet 2012;118:S63-4. doi:10.1016/S0020-7292(12)60002-2.

[5] Yamin A, Bergallo P. Narratives of Essentialism and Exceptionalism: The Challenges and Possibilities of Using Human Rights to Improve Access to Safe Abortion. Health Hum Rights 2017;19:1-11.

[6] Bendavid E, Avila P, Miller G. United States aid policy and induced abortion in sub-Saharan Africa. Bull World Health Organ 2011:873-80. doi:10.2471/BLT.11.091660.

[7] Storeng KT, Palmer J, Daire J, Kloster MO. Behind the scenes: International NGOs' influence on reproductive health policy in Malawi and South Sudan. Glob Public Health 2018;0:1-15. doi:10.1080/17441692.2018.1446545.

[8] Darroch J, Singh S. Trends in contraceptive need and use in developing countries in 2003, 2008, and 2012: an analysis of national surveys. Lancet 2013;381:1756-62. doi:10.1016/S0140. 
[9] Sedgh G, Bearak J, Singh S, Bankole A, Popinchalk A, Ganatra B, et al. Abortion incidence between 1990 and 2014: global, regional, and subregional levels and trends. Lancet 2016;388:258-67. doi:10.1016/S01406736(16)30380-4.

[10] Fetters T, Samandari G, Djemo P, Vwallika B, Mupeta S. Moving from legality to reality: how medical abortion methods were introduced with implementation science in Zambia. Reprod Health 2017;14:1-11. doi:10.1186/s12978-0170289-2.

[11] Sneeringer RK, Billings DL, Ganatra B, Baird TL. Roles of pharmacists in expanding access to safe and effective medical abortion in developing countries: a review of the literature. J Public Health Policy 2012;33:218-29. doi:10.1057/jphp.2012.11.

[12] Singh S, Wulf D, Hussain R, Bankole A, Sedgh G. Abortion Worldwide: A Decade of Uneven Progress Abortion. New York: Guttmacher Institute; 2009.

[13] Assifi AR, Berger B, Tuncalp O, Khosla R, Ganatra B. Women's awareness and knowledge of abortion laws: A systematic review. PLoS One 2016;11. doi:10.1371/journal.pone.0152224.

[14] Cresswell JA, Schroeder R, Dennis M, Owolabi O, Vwalika B, Musheke M, et al. Women's knowledge and attitudes surrounding abortion in Zambia : a cross-sectional survey across three provinces. BMJ Open 2015;6. doi:10.1136/bmjopen-2015-010076.

[15] Moore AM, Jagwe-Wadda G, Bankole A. Mens' attitudes about abortion in Uganda. J Biosoc Sci 2011;43:31-45. doi:10.1017/S0021932010000507. 
[16] Hessini L. A Learning Agenda for Abortion Stigma: Recommendations from the Bellagio Expert Group Meeting. Women Health 2014;54:617-21. doi:10.1080/03630242.2014.919987.

[17] Morroni C, Moodley J. The role of urine pregnancy testing in facilitating access to antenatal care and abortion services in South Africa: a crosssectional study. BMC Pregnancy Childbirth 2006;6:26. doi:10.1186/14712393-6-26.

[18] Harvey P. Medical abortion: the hidden revolution. J Fam Plan Reprod Heal Care 2015;41:193-6. doi:10.1136/jprhc-2014-100990.

[19] Hendrickson C, Fetters T, Mupeta S, Vwallika B, Djemo P, Raisanen K. Client-pharmacy worker interactions regarding medical abortion in Zambia in 2009 and 2011. Int J Gynecol Obstet 2016;132:214-8. doi:10.1016/j.ijgo.2015.07.008.

[20] Aiken A, Scott J, Gomperts R, Trussel J, Worrell M, Aiken C. Requests for Abortion in Latin America Related to Concern about Zika Virus Exposure. N Engl J Med 2016;374. doi:10.1056/NEJMc1603618.

[21] WHO. Expanding health worker roles to help improve access to safe abortion and post-abortion care. 2015.

[22] Footman K, Scott RH, Taleb F, Dijkerman S, Nuremowla S, Reiss K, et al. Feasibility of assessing the safety and effectiveness of menstrual regulation medications purchased from pharmacies in Bangladesh: A prospective cohort study. Contraception 2018;97:152-9. doi:10.1016/j.contraception.2017.08.002. 
[23] Powell-Jackson T, Acharya R, Filippi V, Ronsmans C. Delivering medical abortion at scale: A study of the retail market for medical abortion in Madhya Pradesh, India. PLoS One 2015;10:1-14. doi:10.1371/journal.pone.0120637.

[24] Coast E, Murray SF. "These things are dangerous": Understanding induced abortion trajectories in urban Zambia. Soc Sci Med 2016;153:201-9. doi:10.1016/j.socscimed.2016.02.025.

[25] Moore AM, Dennis M, Anderson R, Bankole A, Abelson A, Vwalika B. Examining the Economic Costs of Legal vs. Illegal Abortions for Women in Zambia. Under review.

[26] Jewkes RK, Gumede T, Westaway MS, Dickson K, Brown H, Rees H. Why are women still aborting outside designated facilities in metropolitan South Africa? BJOG 2005;112:1236-42. doi:10.1111/j.1471-0528.2005.00697.x.

[27] Curtis C, Huber D, Moss-Knight T. Postabortion Family Planning : Addressing the Cycle Of Repeat Unintended Pregnancy and Abortion. Int Perspect Sex Reprod Health 2010;36:44-8.

[28] Parmar D, Leone T, Coast E, Murray SF, Vwalika B, Parmar D, et al. Cost of abortions in Zambia : A comparison of safe abortion and post abortion care. Glob Public Health 2015;12:236-49. doi:10.1080/17441692.2015.1123747.

[29] Palmer JJ, Storeng KT. Building the nation's body: The contested role of abortion and family planning in post-war South Sudan. Soc Sci Med 2016;168:84-92. doi:10.1016/j.socscimed.2016.09.011.

[30] Daire J, Kloster M, Storeng K. Political Priority for Abortion Law Reform in Malawi: Transnational and National Influences. Health Hum Rights 2018;in press. 
[31] Andersen K, Ganatra B, Stucke S, Basnett I, Karki YB, Thapa K. A prospective study of complications from comprehensive abortion care services in Nepal. BMC Public Health 2012;12:9. doi:10.1186/1471-2458-129.

[32] Thaddeus S, Maine D. Too Far to Walk: Maternal Mortality in Context. Soc Sci Med 1994;38:1091-110.

[33] Footman K, Keenan K, Reiss K, Reichwein B, Biswas P, Church K. Medical Abortion Provision by Pharmacies and Drug Sellers in Low- and MiddleIncome Countries: A Systematic Review. Stud Fam Plann 2018;49:57-70. doi:10.1111/sifp.12049.

[34] Marston C, Renedo A, McGowan CR, Portela A. Effects of Community Participation on Improving Uptake of Skilled Care for Maternal and Newborn Health: A Systematic Review. PLoS One 2013;8:1-9. doi:10.1371/journal.pone.0055012.

[35] Beguy D, Mumah J, Gottschalk L. Unintended Pregnancies among Young Women Living in Urban Slums: Evidence from a Prospective Study in Nairobi City, Kenya. PLoS One 2014;9:1-10. doi:10.1371/journal.pone.0101034.

[36] Guttmacher Institute. Adolescents' Need for and Use of Abortion Services In Developing Countries. New York: Guttmacher Institute; 2016. doi:10.4135/9781452276236.n183.

[37] McGinn T, Casey SE. Why don't humanitarian organizations provide safe abortion services? Confl Health 2016;10:8. doi:10.1186/s13031-016-0075-8.

[38] UNFPA. Making Reproductive Rights and Sexual and Reproductive Health A Reality For All. UNFPA; 2008. 
[39] Rehnström Loi U, Gemzell-Danielsson K, Faxelid E, Klingberg-Allvin M, Gasman N, Blandon M, et al. Health care providers' perceptions of and attitudes towards induced abortions in sub-Saharan Africa and Southeast Asia: a systematic literature review of qualitative and quantitative data. BMC Public Health 2015;15:139. doi:10.1186/s12889-015-1502-2.

[40] Lindberg L, Scott RH. Measurement and Mismeasurement of Abortion and Other Pregnancy Outcomes in the National Survey of Family Growth. Popul Assoc Am Annu Meet April 2016, Washington, DC, 2016.

[41] Owolabi OO, Cresswell JA, Vwalika B, Osrin D, Filippi V. Incidence of abortion-related near-miss complications in Zambia: cross-sectional study in Central, Copperbelt and Lusaka Provinces. Contraception 2017;95:167-74. doi:10.1016/j.contraception.2016.08.014.

[42] Rossier C, Guiella G, Ouédraogo A, Thiéba B. Estimating clandestine abortion with the confidants method--results from Ouagadougou, Burkina Faso. Soc Sci Med 2006;62:254-66. doi:10.1016/j.socscimed.2005.05.024.

[43] Heckathon D. Snowball Versus Respondent-driven Sampling. Sociol Methodol 2011;41:355-66. doi:10.1111/j.14679531.2011.01244.x.SNOWBALL.

[44] Miller S, Abalos E, Chamillar M, Ciapponi A, Colaci D, Comande D, et al. Beyond "Too Little, Too Late" and Too Much, Too Soon": A pathway towards evidence-based, respectful maternity care worldwide. Lancet 2016;6736:117. doi:10.1016/S0140-6736(16)31472-6. 
[45] Brahmi D, Maxwell L, Collado ME, Schiavon R, Montaño PC, Sánchez RC. Pharmacy recruitment of misoprostol users in Mexico: a feasibility study. Contraception 2014;90:299. doi:10.1016/j.contraception.2014.05.026.

[46] Glick P. How reliable are surveys of client satisfaction with healthcare services? Evidence from matched facility and household data in Madagascar. Soc Sci Med 2009;68:368-79. doi:10.1016/j.socscimed.2008.09.053.

[47] Smith C, Ngo TD, Gold J, Edwards P, Vannak U, Sokhey L, et al. Effect of a mobile phone-based intervention on post-abortion contraception: a randomized controlled trial in Cambodia. Bull World Health Organ 2015;93:842-50A. doi:10.2471/BLT.15.160267.

[48] The Africa Regional Conference on Abortion. From Research to Policy: Conference Declaration, November 29-December 2, Addis Ababa, Ethiopia: 2016.

[49] Crane B, Hord Smith C. Access to safe abortion: an essential strategy for achieving the millennium development goals to improve maternal health, promote gender equality, and reduce poverty. Millenium Project; 2006.

[50] Footman K, Keenan K, Reichwein B, Church K, Biswas P, Reiss K. A systematic review of medical abortion provision by pharmacy workers in low and middle income countries: Scale, quality and strategies to improve provision practices. Under Rev 2016.

[51] Reiss K, Footman K, Burke E, Diop N, Ndao R, Mane B, et al. Knowledge and provision of misoprostol among pharmacy workers in Senegal: a cross sectional study. BMC Pregnancy Childbirth 2017;17:4-11. doi:10.1186/s12884-017-1394-5. 
[52] Brouwere V De, Zinnen V, Delvaux T. How to conduct Maternal Death Reviews (MDRs) Guidelines and tools for Health Professionals. London: International Federation of Gynecologists and Obstetricians; 2013.

[53] Merali HS, Lipsitz S, Hevelone N, Gawande A a, Lashoher A, Agrawal P, et al. Audit-identified avoidable factors in maternal and perinatal deaths in low resource settings: a systematic review. BMC Pregnancy Childbirth 2014;14:280. doi:10.1186/1471-2393-14-280. 